\title{
Dexamethasone versus Prednisone in Childhood Acute Lymphoblastic Leukemia Treatment: Results of the Indonesian Randomized Trial
}

\author{
Pudjo H. Widjajanto ${ }^{*}$, Eddy Supriyadi', Ignatius Purwanto', Jacqueline Cloos $^{2,3}$, \\ Peter M. vdVen ${ }^{4}$, Sutaryo ${ }^{1}$, Anjo JP. Veerman ${ }^{1,2}$ \\ ${ }^{1}$ Pediatric Hematology and Oncology Division, Department of Pediatrics, Sardjito Hospital, Medical Faculty, Universitas Gadjah \\ Mada, Yogyakarta, Indonesia \\ ${ }^{2}$ Pediatric Oncology/Hematology Division, Department of Pediatrics, VU University Medical Center, Amsterdam, \\ The Netherlands \\ ${ }^{3}$ Department of Hematology, VU University Medical Center, Amsterdam, The Netherlands \\ ${ }^{4}$ Department of Epidemiology and Biostatistics, VU University Medical Center, Amsterdam, The Netherlands \\ Email: *pudjo007@yahoo.com
}

How to cite this paper: Widjajanto, P.H., Supriyadi, E., Purwanto, I., Cloos, J., vdVen, P.M., Sutaryo and JP. Veerman, A. (2017) Dexamethasone versus Prednisone in Childhood Acute Lymphoblastic Leukemia Treatment: Results of the Indonesian Randomized Trial. Journal of Cancer Therapy, 8, 735-750.

https://doi.org/10.4236/jct.2017.88064

Received: June 7, 2017

Accepted: July 31, 2017

Published: August 3, 2017

Copyright $(9) 2017$ by authors and Scientific Research Publishing Inc. This work is licensed under the Creative Commons Attribution International License (CC BY 4.0).

http://creativecommons.org/licenses/by/4.0/

cC) (i) Open Access

\begin{abstract}
Background: Randomized trials report that, compared to prednisone, dexamethasone has reduced CNS relapse and improved event-free survival (EFS), despite a trend toward a higher risk for induction death. Because toxic death is a specific problem in the Indonesian setting, this study compares the outcome of dexamethasone versus prednisone. Methods: In the period 20062011, 196 patients with childhood acute lymphoblastic leukemia (ALL) treated on the Indonesia-ALL-2006 protocol [first standard risk (SR) and later high risk (HR) patients] were randomized to receive dexamethasone or prednisone as steroid. Patients in the dexamethasone $\operatorname{arm}(\mathrm{n}=102$ : $68 \mathrm{SR}, 34 \mathrm{HR})$ received dexamethasone $4 \mathrm{mg} / \mathrm{m}^{2} /$ day (SR) or $6 \mathrm{mg} / \mathrm{m}^{2} /$ day (HR), while the prednisone arm ( $\mathrm{n}=94: 66 \mathrm{SR}, 28 \mathrm{HR})$ received prednisone $40 \mathrm{mg} / \mathrm{m}^{2} /$ day (SR and HR). Results: Patients in the dexamethasone arm showed no significant difference compared to the prednisone arm in abandonment rate $(24.5 \%$ vs. $25.5 \%, P=0.91)$, death rate $(17.7 \%$ vs. $14.9 \%, P=0.54)$, or leukemic events (13.7 vs. $11.7 \%, P=0.59)$. After stratification for risk group, a trend towards a higher death rate was found in the dexamethasone arm of SR patients (16.2 vs. $6.1 \%, P=0.06)$. The 3 -year survival for EFS in SR and HR patients for dexamethasone versus prednisone was $31.5 \% \pm 6.6 \%$ vs. $41.5 \% \pm 5.9 \%(P=0.51)$, for leukemia-free survival (LFS) it was $63.7 \% \pm 9.3 \%$ vs. $74.5 \% \pm 7.6 \%(P=$ 0.47 ), and for overall survival (OS) it was $49.5 \% \pm 7.7 \%$ vs. $69.3 \% \pm 6.1 \%$ ( $P=$ 0.09). Conclusions: In our setting, a trend toward higher induction deaths
\end{abstract}


was observed in the dexamethasone arm of SR patients and the 3-year EFS; LFS and OS rates were lower in the dexamethasone group; however, these differences were not significant.

\section{Keywords}

Dexamethasone versus Prednisone, Childhood ALL, Indonesia

\section{Introduction}

Steroids, either prednisone or dexamethasone, are essential drugs in the remission induction phase of childhood acute lymphoblastic leukemia (ALL) treatment based on their activity against lymphoblasts [1] [2] [3]. In vitro studies and clinical trials it showed that dexamethasone is superior to prednisone in killing lymphoblasts [4] [5] and in lowering the incidence of central nervous system (CNS) involvement due to higher concentration of free drug and greater capacity to penetrate the blood-brain barrier than prednisone [6] [7] [8]. Randomized trials in Western countries have shown that dexamethasone results in higher event-free survival (EFS) and fewer CNS relapses than prednisolone. However, this might be at the expense of higher toxic deaths even though (due to low numbers) this effect did not reach significance [8] [9]. A systematic review and meta-analysis published after our randomization procedure confirmed the findings of significantly lower CNS relapse and reduced events in the dexamethasone group compared with the prednisone group [10]. However, drug-related toxicity was significantly higher with dexamethasone than with prednisone in terms of induction death [8] [11], risk of fractures [12], gastritis and weight gain [13]. With the much higher toxic death rates (17\% - 23\%) reported in low-income countries [14] [15] [16] [17], the toxicity of dexamethasone might prove to be excessive.

Since 1992, the Indonesian protocols for childhood ALL were dexamethasone based rather than prednisone based [16]. However, because doubts arose about the toxicity of dexamethasone, we conducted a prospective randomized study to evaluate whether the type of steroid used might influence the outcome in our local setting. The problems frequently encountered in Indonesia and other lowincome countries (e.g. treatment abandonment, toxic death, resistant disease and relapse) were evaluated.

\section{Methods}

\subsection{Patients}

This prospective study was conducted in the Pediatric Cancer Unit (PCU) of Dr. Sardjito Hospital, Yogyakarta, Indonesia. Childhood ALL patients newly diagnosed during the period from May 22, 2006 until December 28, 2011 (standard risk, SR patients) or from May 1, 2009 until December 28, 2011 (high risk, HR patients) were enrolled in this study. The ethical clearance was obtained 
from the ethic committee of Faculty of Medicine, Universitas Gadjah Mada/ Dr. Sardjito Hospital.

The study was started first in SR patients and later expanded to include HR patients. All patients were treated according to the Indonesia-ALL-2006 protocol. Diagnosis of ALL was primarily based on morphological assessment using the French-American-British (FAB) classification [18] and was supported by immunophenotype examination. Patients with FAB-L3 morphology or mature B-ALL were excluded. The inclusion criteria were: age 0-14 completed years, newly diagnosed, and no prior treatment with steroids or chemotherapy. Informed consent was signed by parents or guardians. Criteria for SR were age 1 - 10 years, WBC less than $50 \times 10^{9} / \mathrm{L}$, no mediastinal mass, no CNS involvement, and B-cell lineage as well as a blast count of less than $1 \times 10^{9} / \mathrm{L}$ after the 1 -week pre-phase treatment. All other patients were classified as HR.

Random allocation into the dexamethasone or prednisone arm was done using a computer program after diagnosis and parental approval. The observation period ended March 23, 2012. The characteristics of the patients are shown in Table 1.

\subsection{Treatment Protocol}

The Indonesia-ALL-2006 protocol was the successor of the first generation of Indonesian national protocols for childhood ALL treatment, namely the WK-

Table 1. Characteristics of patient at diagnosis.

\begin{tabular}{|c|c|c|c|c|c|c|c|}
\hline & \multicolumn{2}{|c|}{ Dexamethasone $(n=102)$} & \multicolumn{2}{|c|}{ Prednisone $(n=94)$} & \multicolumn{2}{|c|}{ Total $(n=196)$} & \multirow[t]{2}{*}{$P$-value } \\
\hline & $\mathrm{n}$ & $\%$ & $\mathrm{n}$ & $\%$ & $\mathrm{n}$ & $\%$ & \\
\hline Risk group & & & & & & & 0.59 \\
\hline Standard risk & 68 & 67.7 & 66 & 70.2 & 134 & 68.4 & \\
\hline High risk & 34 & 33.3 & 28 & 29.8 & 62 & 31.6 & \\
\hline Sex & & & & & & & 0.55 \\
\hline Boy & 51 & 50.0 & 51 & 54.2 & 102 & 52.0 & \\
\hline Girl & 51 & 50.0 & 43 & 45.8 & 94 & 48.0 & \\
\hline Age (years) & & & & & & & 0.88 \\
\hline $1-10$ & 86 & 84.3 & 80 & 85.1 & 166 & 84.7 & \\
\hline$<1$ and $\geq 10$ & 16 & 15.7 & 14 & 14.9 & 30 & 15.3 & \\
\hline WBC $\left(\times 10^{9} / \mathrm{L}\right)$ & & & & & & & 0.54 \\
\hline$<50$ & 80 & 78.4 & 77 & 81.9 & 157 & 80.1 & \\
\hline$\geq 50$ & 22 & 21.6 & 17 & 18.1 & 39 & 19.9 & \\
\hline Immunophenotyping ${ }^{\mathrm{a}}$ & & & & & & & $0.69^{\mathrm{a}}$ \\
\hline T-cell ALL & 4 & 8.9 & 2 & 5.6 & 6 & 7.4 & \\
\hline Precursor B-cell ALL & 41 & 91.1 & 34 & 94.4 & 75 & 72.6 & \\
\hline
\end{tabular}

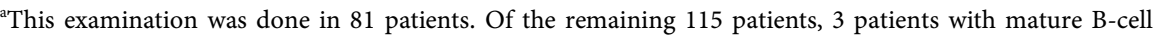

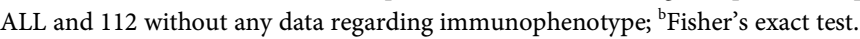


ALL-2000 protocol [19]. The WK-ALL-2000 protocol was adapted from the Dutch ALL-VI protocol and was based on 3-drug induction with dexamethasone as the steroid [20]. In the Indonesia-ALL-2006 protocol (Figure 1), the

\section{INDONESIAN PROTOCOL A. L. L - HR - 2006}

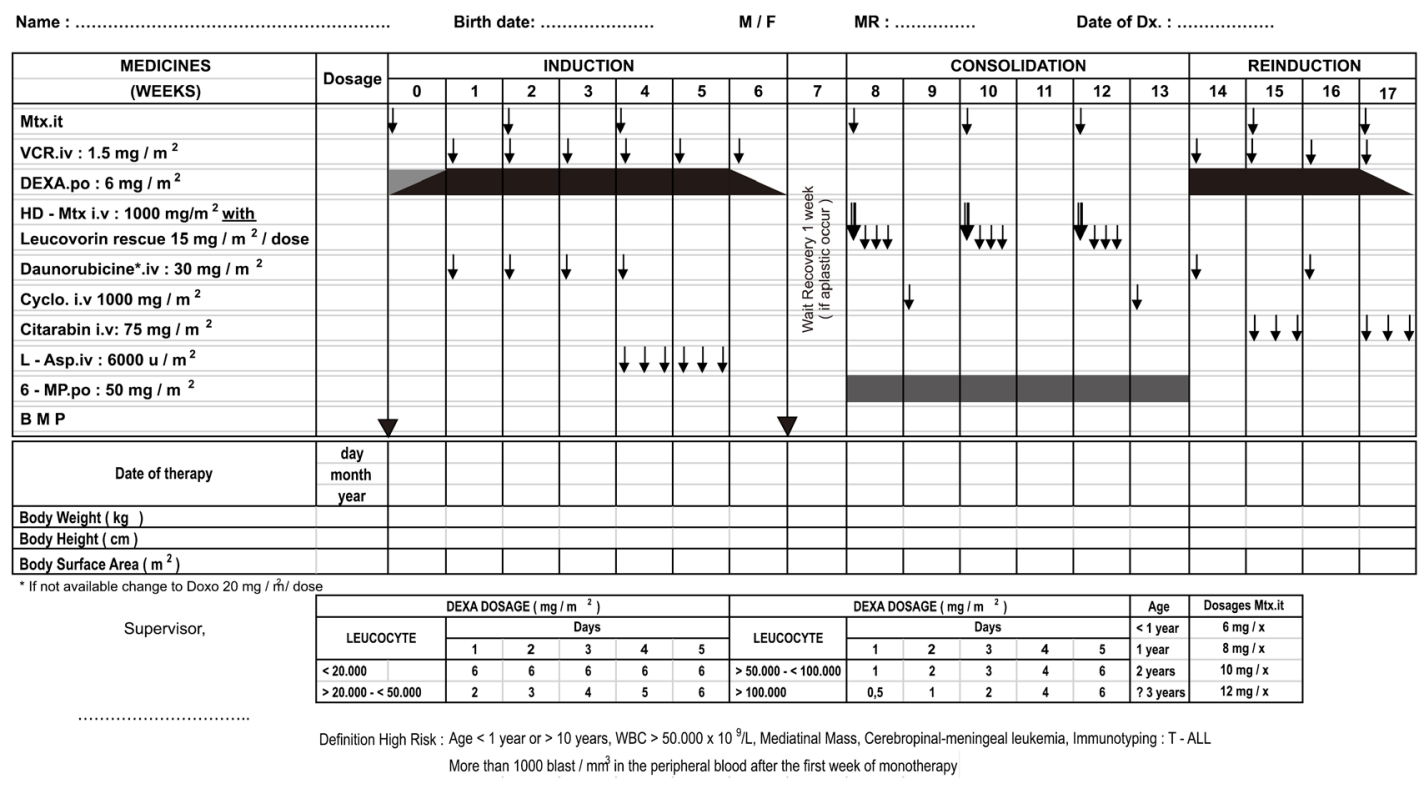

INDONESIAN PROTOCOL A. L. L - HR - MAINTENANCE - 2006

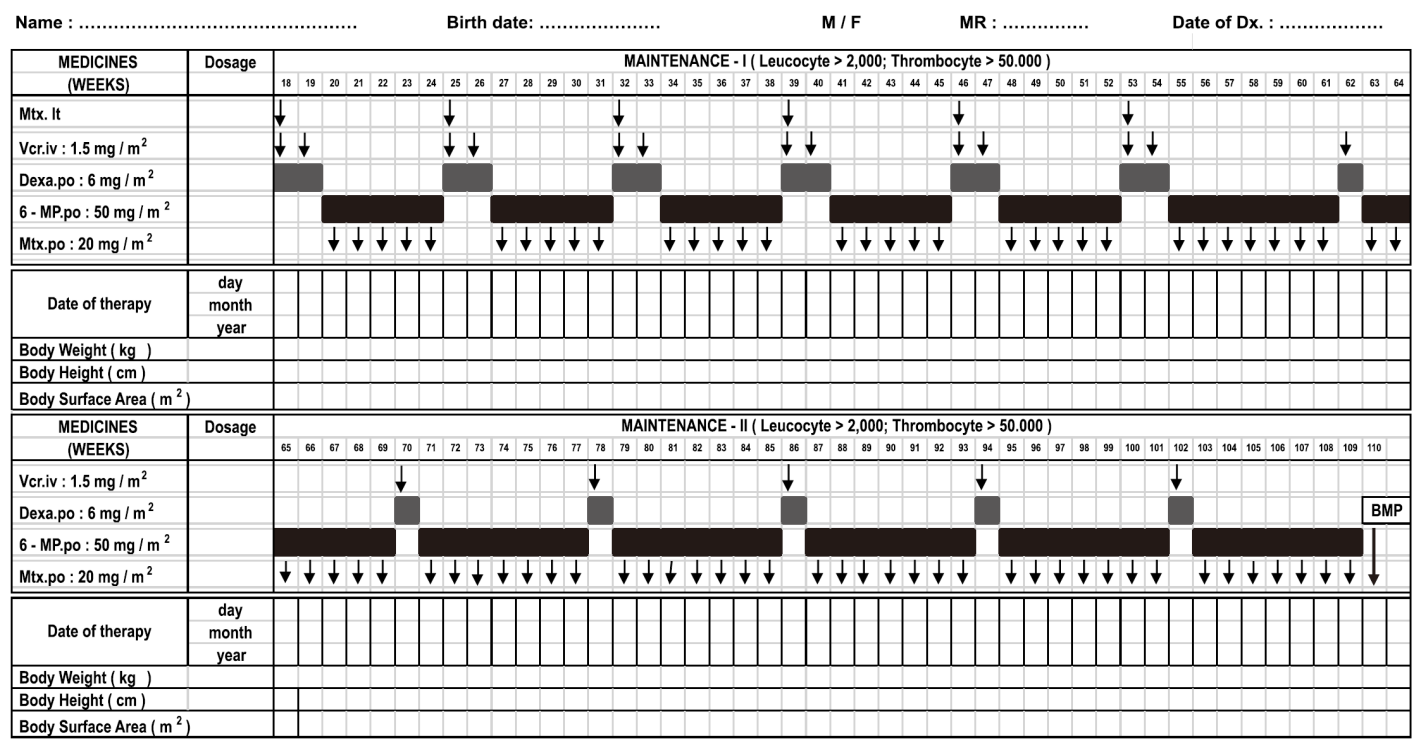

Supervisor,

Figure 1. Indonesia-ALL-2006 protocol for high risk childhood ALL (dexamethasone arm). The re-induction treatment was skipped in SR patients; otherwise, both SR and HR protocol have the same drugs, doses and schedules. Patients in the prednisone arm receive prednisone $60 \mathrm{mg} / \mathrm{m}^{2} /$ day during pre-phase, then $40 \mathrm{mg} / \mathrm{m}^{2} /$ day during induction and maintenance treatment (SR) or prednisone $40 \mathrm{mg} / \mathrm{kg} /$ day during pre-phase, induction, re-induction and maintenance treatment (HR). Patients in the dexamethasone arm received dexamethasone $4 \mathrm{mg} / \mathrm{m}^{2} /$ day (SR), or $6 \mathrm{mg} / \mathrm{m}^{2} /$ day (HR). 
induction consisted of 4 drugs including 4 doses of daunorubicin $\left(30 \mathrm{mg} / \mathrm{m}^{2}\right)$ for SR and HR patients. In the case that daunorubicin was not available it was replaced by doxorubicin at a dose of $20 \mathrm{mg} / \mathrm{m}^{2}$. After induction patients received a consolidation and maintenance treatment. A re-induction course was inserted after the consolidation treatment in HR patients. Patients in the dexamethasone arm received prednisone $60 \mathrm{mg} / \mathrm{m}^{2} /$ day during one week pre-phase, then dexamethasone $4 \mathrm{mg} / \mathrm{m}^{2} /$ day during induction, and in blocks during maintenance for SR patients; or dexamethasone $6 \mathrm{mg} / \mathrm{m}^{2} /$ day during one week prephase, as well as in induction, re-induction and maintenance treatment blocks for HR patients. Patients in the prednisone arm received prednisone $60 \mathrm{mg} / \mathrm{m}^{2}$ / day during pre-phase, then $40 \mathrm{mg} / \mathrm{m}^{2} /$ day during induction and maintenance treatment blocks (SR patients) or prednisone $40 \mathrm{mg} / \mathrm{m}^{2} /$ day during pre-phase, induction, re-induction and in maintenance treatment blocks (HR patients). At the end of the pre-phase SR patients with a peripheral lymphoblast count of more than $1 \times 10^{9} / \mathrm{L}$ were switched to the HR protocol.

\subsection{Outcomes and Statistical Analysis}

The aim of this study was to compare the efficacy of dexamethasone versus prednisone in the Indonesia-ALL-2006 treatment protocol. The outcomes were death rate, abandonment rate and leukemic events (resistant disease and relapse). We calculated EFS from the date at start of treatment to the date of an event which occurred first: death, abandonment, resistant disease or relapse. LFS was calculated from the date at start treatment to the date of resistant disease confirmation at the end of induction, or first relapse after achievement of complete remission (CR). The overall survival (OS) was calculated from the date at start of treatment to the date of death by any cause. CR was determined at the end of induction treatment and defined as no detectable lymphoblasts in peripheral blood or cerebrospinal fluid and less than 5\% lymphoblasts in active hemopoietic marrow, and no physical signs of infiltrative leukemic cells anywhere. Patients who were alive without any event were censored at the date of analysis on March 23, 2012. Patients who abandoned treatment whilst in CR, or who relapsed, were considered failures at the time of their withdrawal or relapse. All families of patients were personally contacted on the date of analysis to check the patient's status.

The EFS, LFS and OS curves were estimated using the Kaplan-Meier method and compared using the log-rank test. A p-value $\leq 0.05$ was used as level for statistical significance. The data were analyzed using the SPSS version 13.0.

\section{Results}

During the study period, 291 patients with ALL were admitted to Dr. Sardjito Hospital, Yogyakarta. Of these, 62 did not meet the inclusion criteria due to: refusal of treatment (23), previous treatment with steroids or ALL treatment (9), death before treatment started (8), L3 morphology (8), age at diagnosis $\geq 15$ years (5), mixed leukemia (4), moved to other treatment protocols (4), or to 
another hospital (1). The remaining 196 patients consisted of 134 SR and $62 \mathrm{HR}$ patients. Immunophenotyping was done in 84 patients and confirmed as T-cell (6) or precursor B-cell ALL (75), while 3 patients were characterized as mature B-cell lineage ALL and thus excluded from this study. For 112 patients no data on immunophenotype were available since the examination was not yet developed at the time of diagnosis, or due to technical problems such as lack of specimen, clotted specimen or inconclusive results. At the time of analysis all patients had finished induction treatment or experienced induction failure. The median follow-up of patients in remission since entering treatment until the time of analysis was 22 (range 3 - 60) months in the dexamethasone arm and 26 (range 4 - 67) months in the prednisone arm $(P=0.25)$. Of the 196 patients enrolled in this study, 102 (52\%) were randomized to the dexamethasone arm and 94 (48\%) to the prednisone arm. The characteristics at diagnosis such as risk group, age, sex, WBC group and immunophenotype were equally distributed between the dexamethasone arm and prednisone arm (Table 1). The median age was 4.0 years (range 2 months - 14 years) in the dexamethasone arm and 4.0 years (range 5 months - 14 years) in the prednisone arm.

Of the 196 patients, 141 (72.4\%) patients achieved CR: 71/102 (69.6\%) patients in the dexamethasone arm and 71/94 (75.5\%) in the prednisone arm $(P$ $=0.35)$ (Table 2). The clinical outcomes in the overall ALL patient group showed no significant differences between the dexamethasone and prednisone arms in terms of abandonment of treatment $(24.5 \%$ vs. $25.5 \%, P=0.91)$, death

Table 2. Clinical outcomes during induction treatment and overall in SR and HR patients.

\begin{tabular}{|c|c|c|c|c|c|c|c|c|c|}
\hline & \multicolumn{2}{|c|}{$\begin{array}{l}\text { Dexamethasone } \\
(\mathrm{n}=102)\end{array}$} & \multicolumn{2}{|c|}{$\begin{array}{c}\text { Prednisone } \\
(\mathrm{n}=94)\end{array}$} & \multicolumn{2}{|c|}{$\begin{array}{c}\text { Total } \\
(n=196)\end{array}$} & \multirow[t]{2}{*}{ OR } & \multirow[t]{2}{*}{$95 \% \mathrm{CI}$} & \multirow[t]{2}{*}{$P$-value } \\
\hline & $\mathrm{n}$ & $\%$ & $\mathrm{n}$ & $\%$ & $\mathrm{n}$ & $\%$ & & & \\
\hline \multicolumn{10}{|l|}{ Induction treatment } \\
\hline Complete remission & 71 & 69.6 & 71 & 75.5 & 142 & 72.4 & & & \\
\hline Induction failures & 31 & 30.4 & 23 & 24.5 & 54 & 27.6 & 0.74 & $0.39-1.40^{\mathrm{a}}$ & $0.35^{1}$ \\
\hline Abandonment & 12 & 11.7 & 11 & 11.7 & 23 & 11.7 & 0.92 & $0.38-2.21^{\mathrm{a}}$ & $0.85^{1}$ \\
\hline Death & 14 & 13.7 & 8 & 8.5 & 22 & 11.3 & 0.57 & $0.23-1.45^{\mathrm{a}}$ & $0.23^{1}$ \\
\hline Resistant disease & 5 & 4.9 & 4 & 4.3 & 9 & 4.6 & 0.80 & $0.21-3.10^{\mathrm{a}}$ & $1.00^{2}$ \\
\hline \multicolumn{10}{|l|}{ Overall events } \\
\hline Continuous CR & 45 & 44.1 & 45 & 47.9 & 90 & 45.9 & & & \\
\hline Treatment failures & 57 & 55.9 & 49 & 52.1 & 106 & 54.1 & 0.86 & $0.49-1.51^{\mathrm{b}}$ & $0.60^{1}$ \\
\hline Abandonment & 25 & 24.5 & 24 & 25.5 & 49 & 25.0 & 0.96 & $0.48-1.93^{\mathrm{b}}$ & $0.91^{1}$ \\
\hline Death & 18 & 17.7 & 14 & 14.9 & 32 & 16.3 & 0.78 & $0.34-1.75^{\mathrm{b}}$ & $0.54^{1}$ \\
\hline Leukemic event & 14 & 13.7 & 11 & 11.7 & 25 & 12.8 & 0.79 & $0.32-1.92^{\mathrm{b}}$ & $0.59^{1}$ \\
\hline
\end{tabular}

OR, odds ratio for prednisone arm relative to dexamethasone arm; CI, confidence interval; CR, complete remission. ${ }^{a} \mathrm{ORs}$ for any induction failure and specific induction failures (CR during induction is taken as the reference outcome category). ${ }^{b} \mathrm{ORs}$ for any treatment failures and specific treatment failures (continuous CR is taken as the reference outcome category). ${ }^{1}$ Chi-square test. ${ }^{2}$ Fisher's exact test. 
(17.7\% vs. $14.9, P=0.54)$, leukemic events $(13.7 \%$ vs. $11.7 \%, P=0.59)$ and continuous $\mathrm{CR}$ achievement $(44.1 \%$ vs. $47.9 \%, P=0.60)$. In both arms, all relapses were hematological relapses and $76 \%$ occurred during treatment, mostly in maintenance treatment (65\%). The median time to relapse after achievement of CR was 16 (range 10 - 30) months in the dexamethasone arm and 22 (range 2 - 29) months in the prednisone arm $(P=0.88)$. No secondary malignancy was found during this study.

Separate analysis of SR patients revealed a trend for a higher death rate during induction in the dexamethasone compared to the prednisone arm $(16.2 \%$ vs. $6.1 \%, P=0.06)$ with equal abandonment and leukemic events in both arms (Table 3). In HR patients the dexamethasone versus the prednisone arms showed no significant difference in terms of treatment abandonment, death and leukemic events either during induction or overall (Table 4).

The 3-year EFS in the dexamethasone arm was $31.5 \% \pm 6.6 \%$ versus $41.5 \% \pm$ $5.9 \%(P=0.51)$ in the prednisone arm (Figure 2(a)). The 3-year LFS in the dexamethasone arm versus the prednisone arm was $63.7 \% \pm 9.3 \%$ versus $74.5 \%$ $\pm 7.6 \%(P=0.47)$ (Figure 2(b)) and the 3-year OS in the dexamethasone arm versus the prednisone arm was $49.5 \% \pm 7.7 \%$ versus $69.3 \% \pm 6.1 \%(P=0.09)$ as shown in Figure 2(c).

\section{Discussion}

This study compared the efficacy of dexamethasone versus prednisone in newly

Table 3. Clinical outcomes during induction treatment and overall in SR patients.

\begin{tabular}{|c|c|c|c|c|c|c|c|c|c|}
\hline & \multicolumn{2}{|c|}{$\begin{array}{l}\text { Dexamethasone } \\
4 \mathrm{mg} / \mathrm{m}^{2}(\mathrm{n}=68)\end{array}$} & \multicolumn{2}{|c|}{$\begin{array}{c}\text { Prednisone } \\
40 \mathrm{mg} / \mathrm{m}^{2} \\
(\mathrm{n}=66)\end{array}$} & \multicolumn{2}{|c|}{$\begin{array}{c}\text { Total } \\
(\mathrm{n}=134)\end{array}$} & \multirow[t]{2}{*}{ OR } & \multirow[t]{2}{*}{$95 \% \mathrm{CI}$} & \multirow[t]{2}{*}{$P$-value } \\
\hline & $\mathrm{n}$ & $\%$ & $\mathrm{n}$ & $\%$ & $\mathrm{n}$ & $\%$ & & & \\
\hline \multicolumn{10}{|l|}{ Induction treatment } \\
\hline Complete remission & 48 & 70.6 & 52 & 78.8 & 100 & 74.6 & & & \\
\hline Induction failures & 20 & 29.4 & 14 & 21.2 & 34 & 25.4 & 0.65 & $0.29-1.42^{\mathrm{a}}$ & $0.27^{1}$ \\
\hline Abandonment & 8 & 11.7 & 7 & 10.6 & 15 & 11.2 & 0.81 & $0.27-2.39^{\mathrm{a}}$ & $0.70^{1}$ \\
\hline Death & 11 & 16.2 & 4 & 6.1 & 15 & 11.2 & 0.34 & $0.10-1.13^{\mathrm{a}}$ & $0.06^{1}$ \\
\hline Resistant disease & 1 & 1.5 & 3 & 4.5 & 4 & 3.0 & 2.77 & $0.28-27.54^{\mathrm{a}}$ & $0.62^{2}$ \\
\hline \multicolumn{10}{|l|}{ Overall events } \\
\hline Continuous CR & 31 & 45.6 & 35 & 53.1 & 66 & 49.3 & & & \\
\hline Treatment failures & 37 & 54.4 & 31 & 46.9 & 68 & 50.7 & 0.74 & $0.38-1.46^{\mathrm{b}}$ & $0.39^{1}$ \\
\hline Abandonment & 16 & 23.5 & 13 & 19.7 & 29 & 21.6 & 0.72 & $0.30-1.73^{\mathrm{b}}$ & $0.46^{1}$ \\
\hline Death & 13 & 19.2 & 9 & 13.6 & 22 & 16.4 & 0.61 & $0.23-1.63^{b}$ & $0.32^{1}$ \\
\hline Leukemic event & 8 & 11.7 & 9 & 13.6 & 17 & 12.7 & 0.99 & $0.34-2.90^{\mathrm{b}}$ & $0.99^{1}$ \\
\hline
\end{tabular}

OR, odds ratio for prednisone arm relative to dexamethasone arm; CI, confidence interval; CR, complete remission. ${ }^{a} \mathrm{ORs}$ for any induction failure and specific induction failures (CR during induction is taken as

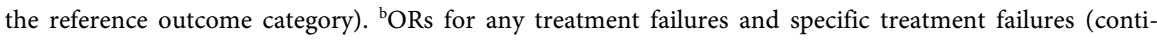
nuous CR is taken as the reference outcome category). ${ }^{1}$ Chi-square test. ${ }^{2}$ Fisher's exact test. 
Table 4. Clinical outcomes during induction treatment and overall in HR patients.

\begin{tabular}{|c|c|c|c|c|c|c|c|c|c|}
\hline & \multicolumn{2}{|c|}{$\begin{array}{l}\text { Dexamethasone } \\
6 \mathrm{mg} / \mathrm{m}^{2}(\mathrm{n}=34)\end{array}$} & \multicolumn{2}{|c|}{$\begin{array}{c}\text { Prednisone } \\
40 \mathrm{mg} / \mathrm{m}^{2} \\
(\mathrm{n}=28)\end{array}$} & \multicolumn{2}{|c|}{$\begin{array}{c}\text { Total } \\
(n=62)\end{array}$} & \multirow[t]{2}{*}{ OR } & \multirow[t]{2}{*}{$95 \% \mathrm{CI}$} & \multirow[t]{2}{*}{ P-value } \\
\hline & $\mathrm{n}$ & $\%$ & $\mathrm{n}$ & $\%$ & $\mathrm{n}$ & $\%$ & & & \\
\hline \multicolumn{10}{|l|}{ Induction treatment } \\
\hline Complete remission & 23 & 67.6 & 19 & 67.9 & 42 & 67.7 & & & \\
\hline Induction failures & 11 & 32.4 & 9 & 32.3 & 20 & 32.3 & 0.99 & $0.34-2.89^{\mathrm{a}}$ & $0.99^{2}$ \\
\hline Abandonment & 4 & 11.8 & 4 & 14.3 & 8 & 12.9 & 1.21 & $0.27-5.50^{\mathrm{a}}$ & $1.00^{2}$ \\
\hline Death & 3 & 8.8 & 4 & 14.3 & 7 & 11.3 & 1.61 & $0.32-8.12^{\mathrm{a}}$ & $0.69^{2}$ \\
\hline Resistant disease & 4 & 11.8 & 1 & 3.7 & 5 & 8.1 & 0.30 & $0.03-2.94^{\mathrm{a}}$ & $0.38^{2}$ \\
\hline \multicolumn{10}{|l|}{ Overall events } \\
\hline Continuous CR & 14 & 41.2 & 11 & 39.3 & 25 & 40.3 & & & \\
\hline Treatment failures & 20 & 58.8 & 17 & 60.7 & 37 & 59.7 & 1.08 & $0.39-3.00^{\mathrm{b}}$ & $0.88^{1}$ \\
\hline Abandonment & 9 & 26.5 & 10 & 35.7 & 19 & 30.6 & 1.41 & $0.43-4.68^{\mathrm{b}}$ & $0.57^{1}$ \\
\hline Death & 5 & 14.7 & 5 & 17.8 & 10 & 16.2 & 1.27 & $0.29-5.55^{\mathrm{b}}$ & $1.00^{2}$ \\
\hline Leukemic event & 6 & 17.6 & 2 & 7.2 & 8 & 12.9 & 0.42 & $0.07-2.53^{\mathrm{b}}$ & $0.43^{2}$ \\
\hline
\end{tabular}

OR, odds ratio for prednisone arm relative to dexamethasone arm; CI, confidence interval; CR, complete remission. ${ }^{a} \mathrm{ORs}$ for any induction failure and specific induction failures (CR during induction is taken as

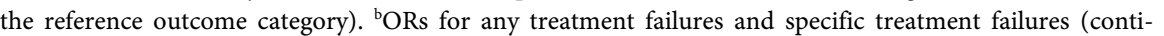
nuous $\mathrm{CR}$ is taken as the reference outcome category). ${ }^{1} \mathrm{Chi}$-square test. ${ }^{2}$ Fisher's exact test.

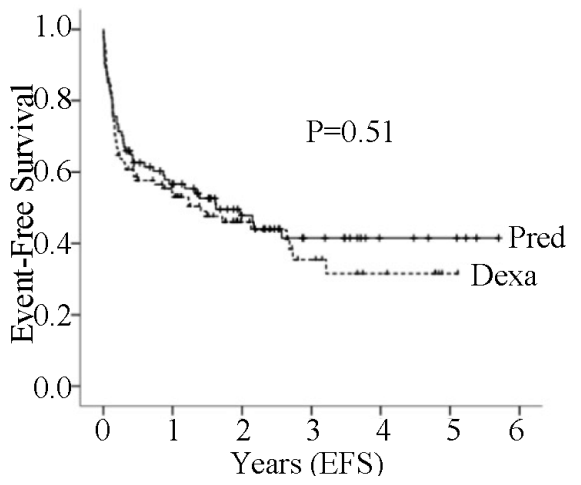

(a)

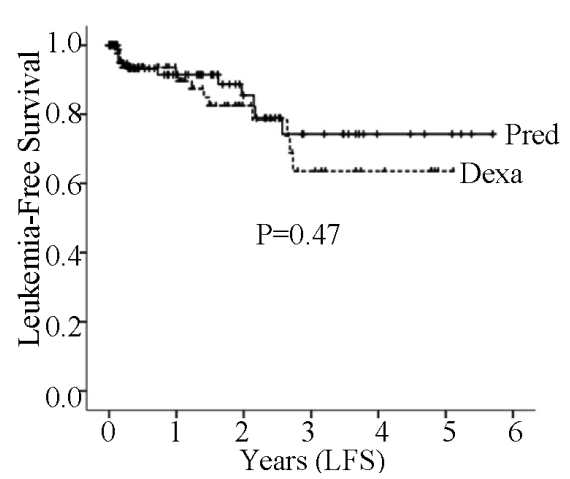

(b)

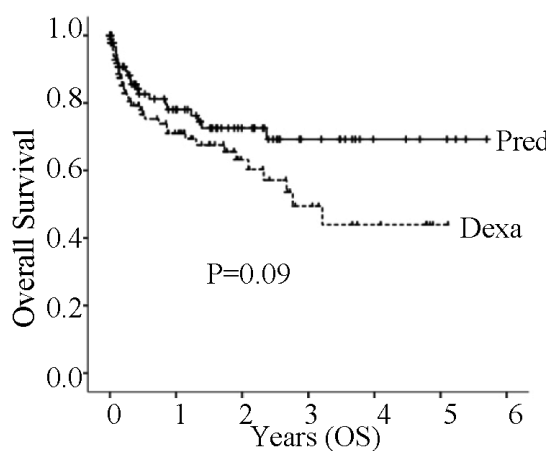

(c)

Figure 2. Kaplan-Meier overall survival curves of: (a) event-free survival; (b) leukemia-free survival; and (c) overall survival of the entire group (standard and high-risk together) of childhood ALL patients treated according to the Indonesia-ALL-2006 protocol. 
diagnosed childhood ALL patients treated in a low-income setting in Indonesia. The Indonesian protocols have utilized dexamethasone as steroid for more than 15 years based on the evidence of a lower incidence of meningeal leukemia in childhood ALL patients treated with dexamethasone instead of prednisone [7] and the high cure rate achieved with the dexamethasone-based Dutch ALL-VI protocol [20]. However, a UK randomized study showed that dexamethasone was also associated with more toxicities than prednisone, i.e. treatment-related death in the dexamethasone group was higher than in the prednisone group (4.6\% vs. $2.4 \%, P=\mathrm{ns}$ ) [8]. Considering that toxic death is much higher in Indonesia and other low-income countries compared with Western countries, the question arose whether dexamethasone might be too toxic in the Indonesian setting. The present study was conducted to address this question.

However, the outcomes in the overall ALL cohort showed no significant differences between the dexamethasone and the prednisone arms, including rates of treatment abandonment, death and leukemic events. In our setting, refusal or abandonment of treatment and toxic death during induction treatment or in remission were the major causes of treatment failure. These adverse events occurred in appreciably higher rates than in Western countries where abandonment is almost non-existent and the death rate is reported to be $1 \%$ 5\% [21] [22] [23] [24] [25]. The high level of treatment refusal and abandonment, and toxic death rates, may represent problems typically seen in low or medium-income countries [14] [15] [16] [17] [19] [26] [27] that lead to inferior survival rates compared to Western studies. Studies in our PCU showed that abandonment of treatment is due to multi-factorial causes related to financial issues (i.e. occurring more often among poorer patients), difficulty with transportation to the hospital, experienced traumatic side-effects, socio-economic status, family perception of disease curability, and lack of professionalism of the health provider (including their attitude/communication skills in ensuring compliance with treatment of patients and parents) [16] [28] [29] [30] [31] [32]. Compared with children enrolled at the implementation of the Indonesian childhood ALL protocol during 1997-2002 [16], the ALL children in the present study (2006-2011) showed a slight reduction in treatment refusal rate $(11 \%$ or $18 / 164$ vs. $8 \%$ or $23 / 291, P=0.27)$ and abandonment rate $(27 \%$ or $39 / 143$ vs. $25 \%$ or $49 / 196, P=0.64$ ); however, both events remain prominent in our daily practice. Many programs have been developed to overcome this problem, including the introduction of a structured parental education program, improvement of access to medicine donation [33], development of human resources and PCU infrastructure, together with the issuing of a government health insurance program intended for poor people during the last 8 years [34].

Compared with the previous study in our PCU [16], the toxic death rate has reduced from $23 \%$ (38/164) to $16 \%$ (32/196); however, the follow-up procedure between the former protocol and the current protocol differs considerably. The finding that the toxic death rate mostly occurred during induction treatment suggests the important role of supportive care for the life-threatening conditions 
during this phase. Our study on patients treated with the less intensive Indonesian WK-ALL-2000 protocol (1999-2005) in our PCU had resulted in severe neutropenia during induction treatment with a median nadir of absolute neutrophil count (ANC) of 165 (range 5 - 25,480) cells/ $\mu \mathrm{L}$ [35]. It is generally assumed that lack of access to supportive care is the cause of the high toxic death rates in low-income countries. Separate analysis in the SR patients revealed that the dexamethasone arm tended to have a higher induction death rate (16.2\%) than patients in the prednisone arm $(6.1 \% ; P=0.06)$. This result is in line with the UKMRC ALL97 study which also found a higher early death ( $<60$ days) rate in the dexamethasone group than in the prednisolone group ( $1.8 \%$ vs. $0.7 \%, P=$ 0.07 ); however, in that study the absolute number was too low to achieve significance [8]. A possible explanation for this could be a notable tendency towards higher septicemia and induction death in childhood ALL treated with dexamethasone than with prednisone or prednisolone [10] [11] [25] [36]. The administration of an anthracycline during induction will augment the toxicity of dexamethasone, as demonstrated by Belgaumi et al. [13]. In the UKALL VIII Study those who received daunorubicin during induction experienced twice as many induction failures (non-remitters + deaths) compared with those who did not receive it (6\% vs. $3 \%$ ). Early remission death rates were also higher in those who received daunorubicin ( $8 \%$ vs. $4 \%$ of remitters) [37]. Based on consensus emerging from the Indonesian Pediatric Hematology and Oncology working group meeting in 2005, the Indonesia-ALL-2006 protocol introduced anthracycline (4 doses of daunorubicin $30 \mathrm{mg} / \mathrm{m}^{2}$ or doxorubicin $20 / \mathrm{m}^{2}$ ) as the fourth drug during induction in both SR and HR patients. In retrospect this decision may have resulted in more pronounced life-threatening conditions and a higher death rate in the SR group. This is especially relevant in a setting such as Indonesia with its high incidence rate of infections and limited access to supportive care. Studies in Italy, USA and the UK showed that SR patients treated with a 3-drug induction without anthracycline achieved CR rates of about $95 \%$ with a 5 -year overall EFS of $56 \%$ - 83\% [9] [37] [38].The Dutch protocol ALL-6 and ALL-9, both dexamethasone-based protocols with 3-drug induction for non-HR patients, have generated an overall 5-year EFS of $82 \%$ and $84 \%$, respectively [39] [40]. This outcome might be related to the better supportive care in Western countries, but perhaps also to the less toxicity in the 3-drug induction protocol thus less induction deaths. In the present study, further analysis in the HR group showed no significantly different outcomes between patients in the dexamethasone and the prednisone arms.

As reported by studies in Western countries, dexamethasone is superior to prednisone in preventing relapse, particularly in the CNS [7] [8] [9]. This finding could not be confirmed in our study since all relapses in both arms were hematological ones. In our PCU, lack of experience in diagnosis of CNS relapse may have obscured the finding of CNS relapses. In addition, a short follow-up period may explain why most relapse occurred during maintenance treatment. In terms of protocol efficacy, in the present study the EFS, LFS, and OS showed 
no significant difference between the dexamethasone and the prednisone arms. However, the prednisone arm showed a trend to have a higher probability of OS at 4 years $(69.3 \pm 6.1 \%$ vs. $44.0 \pm 8.6 \%, P=0.09)$ than the dexamethasone arm. The non-superior outcome of dexamethasone arm could be partly explained by the administration of a less effective dose of dexamethasone in SR patients. The CCG-1922 study using prednisone $40 \mathrm{mg} / \mathrm{m}^{2}$ vs. dexamethasone $6 \mathrm{mg} / \mathrm{m}^{2}$ during induction showed significantly better EFS in the dexamethasone arm [41]. A meta-analysis of 8 Western studies [10] showed a significant reduction of event rate (death from any cause, refractory or relapsed leukemia, or second malignancy) in the dexamethasone arm than in the prednisone arm at a ratio of prednisone and dexamethasone of $<7$. The event rate was the same in prednisone and dexamethasone when the ratio was $\geq 7$. In terms of preventing relapse, dexamethasone significantly reduced CNS relapse compared with prednisone; this applied to a ratio of prednisone and dexamethasone of both $<7$ or $\geq 7$ [10]. The meta-analysis concludes that dexamethasone is more efficacious than prednisone in induction treatment for childhood ALL. However, dexamethasone is also more toxic. The Indonesian childhood ALL protocol for HR used 40 $\mathrm{mg} / \mathrm{m}^{2}$ for prednisone and $6 \mathrm{mg} / \mathrm{m}^{2}$ for dexamethasone, whereas the SR group used the lower dose of dexamethasone $\left(40 \mathrm{mg} / \mathrm{m}^{2}\right.$ for prednisone and $4 \mathrm{mg} / \mathrm{m}^{2}$ for dexamethasone). Nevertheless, the induction deaths in the SR dexamethasone group (16.2\%) were almost three-fold higher than in the prednisone arm $(6.1 \% ; P=0.06)$ (Table 2). Although there is no consensus on dose conversion between dexamethasone and prednisone, the typical conversion between prednisone and dexamethasone is $1 \mathrm{mg}$ dexamethasone equivalent to $7 \mathrm{mg}$ prednisone, or dexamethasone $6 \mathrm{mg}$ as 'equivalent' to prednisone $40 \mathrm{mg}$ (as used in many studies).

It is noteworthy that the treatment outcome of childhood ALL patients in Indonesia has advanced during the last decade, with increasing 3-year EFS from about $20 \%$ in the WK-ALL-2000 protocol to about $37 \%$ in the Indonesia-ALL2006 protocol. Although this achievement can in no way be compared to studies in Western countries that report cure rates of over $80 \%$ [42], our achievement shows that childhood ALL can be treated successfully in a low-income situation such as in Indonesia. This progress illustrates the benefit of our twinning program with the VU University Medical Center (Amsterdam, the Netherlands) [19], which generated research projects and significantly improved our knowledge related to treating childhood cancer.

In an attempt to obtain better outcomes from the Indonesia-ALL-2006 protocol, we recommend to skip the anthracyclines from induction treatment in the SR patients and to continue the randomization of dexamethasone and prednisone during a 3-drug induction for SR patients in an Indonesian multicenter study. Further study may randomize the dose of 40 or $60 \mathrm{mg} / \mathrm{m}^{2}$ prednisone versus $6 \mathrm{mg} / \mathrm{m}^{2}$ dexamethasone. Our study supports the opinion advocated by Hunger et al. [43] that developing a protocol in countries with poor supportive care, and where few children are currently being cured, should be performed 
with extreme caution with regard to potential toxic and drug-related lifethreatening complications.

The limitation of this study was the small sample size. Since the number of newly diagnosed childhood ALL in our PCU is increasing, as also seen in others PCU in Indonesia, the national multicenter data involving the bigger number of patients should be analysed.

\section{Acknowledgements}

The authors thank the KWF and Estella Fonds (the Netherlands) for their excellent financial support of the twinning program between VU University (Amsterdam) and Universitas Gadjah Mada, Yogyakarta, and for their generous support of research and medication for childhood ALL treatment in Dr. Sardjito Hospital, Yogyakarta, Indonesia.

\section{Conflict of Interest}

All authors declare that there are no conflicts of interest.

\section{References}

[1] Harmon, J.M., Norman, M.R., Fowlkes, B.J. and Thompson, E.B. (1979) Dexamethasone Induces Irreversible G1 Arrest and Death of a Human Lymphoid Cell Line. Journal of Cellular Physiology, 98, 267-278. https://doi.org/10.1002/jcp.1040980203

[2] Baxter, G.D., Collins, R.J., Harmon, B.V., Kumar, S., Prentice, R.L., Smith, P.J. and Lavin, M.F. (1989) Cell Death by Apoptosis in Acute Leukaemia. Journal of Pathology, 158, 123-129. https://doi.org/10.1002/path.1711580207

[3] Johnson, B.H., Ayala-Torres, S., Chan, L.N., El-Naghy, M. and Thompson, E.B. (1997) Glucocorticoid/Oxysterol-Induced DNA Lysis in Human Leukemic Cells. Journal of Steroid Biochemistry and Molecular Biology, 61, 35-45. https://doi.org/10.1016/S0960-0760(96)00256-7

[4] Ito, C., Evans, W.E., McNinch, L., Coustan-Smith, E., Mahmoud, H., Pui, C.H. and Campana, D. (1996) Comparative Cytotoxicity of Dexamethasone and Prednisolone in Childhood Acute Lymphoblastic Leukemia. Journal of Clinical Oncology, 14, 2370-2376. https://doi.org/10.1200/JCO.1996.14.8.2370

[5] Kaspers, G.J., Veerman, A.J., Popp-Snijders, C., Lomecky, M., Van Zantwijk, C.H., Swinkels, L.M., Van Wering, E.R. and Pieters, R. (1996) Comparison of the Antileukemic Activity in Vitro of Dexamethasone and Prednisolone in Childhood Acute Lymphoblastic Leukemia. Medical and Pediatric Oncology, 27, 114-121. https://doi.org/10.1002/(SICI)1096-911X(199608)27:2<114::AID-MPO8>3.0.CO;2-I

[6] Balis, F.M., Lester, C.M., Chrousos, G.P., Heideman, R.L. and Poplack, D.G. (1987) Differences in Cerebrospinal Fluid Penetration of Corticosteroids: Possible Relationship to the Prevention of Meningeal Leukemia. Journal of Clinical Oncology, 5, 202-207. https://doi.org/10.1200/JCO.1987.5.2.202

[7] Jones, B., Freeman, A.I., Shuster, J.J., Jacquillat, C., Weil, M., Pochedly, C., Sinks, L., Chevalier, L., Maurer, H.M., Koch, K., et al. (1991) Lower Incidence of Meningeal Leukemia When Prednisone Is Replaced by Dexamethasone in the Treatment of Acute Lymphocytic Leukemia. Medical and Pediatric Oncology, 19, 269-275.

https://doi.org/10.1002/mpo.2950190411

[8] Mitchell, C.D., Richards, S.M., Kinsey, S.E., Lilleyman, J., Vora, A. and Eden, T.O. 
(2005) Medical Research Council Childhood Leukaemia Working, Benefit of Dexamethasone Compared with Prednisolone for Childhood Acute Lymphoblastic Leukaemia: Results of the UK Medical Research Council ALL97 Randomized Trial. British Journal of Haematology, 129, 734-745. https://doi.org/10.1111/j.1365-2141.2005.05509.x

[9] Gaynon, P.S., Trigg, M.E., Heerema, N.A., Sensel, M.G., Sather, H.N., Hammond, G.D. and Bleyer, W.A. (2000) Children's Cancer Group Trials in Childhood Acute Lymphoblastic Leukemia: 1983-1995. Leukemia, 14, 2223-2233.

https://doi.org/10.1038/sj.leu.2401939

[10] Teuffel, O., Kuster, S.P., Hunger, S.P., Conter, V., Hitzler, J., Ethier, M.C., Shah, P.S., Beyene, J. and Sung, L. (2011) Dexamethasone versus Prednisone for Induction Therapy in Childhood Acute Lymphoblastic Leukemia: A Systematic Review and Meta-Analysis. Leukemia, 25, 1232-1238. https://doi.org/10.1038/leu.2011.84

[11] Hurwitz, C.A., Silverman, L.B., Schorin, M.A., Clavell, L.A., Dalton, V.K., Glick, K.M., Gelber, R.D. and Sallan, S.E. (2000) Substituting Dexamethasone for Prednisone Complicates Remission Induction in Children with Acute Lymphoblastic Leukemia. Cancer, 88, 1964-1969. https://doi.org/10.1002/(SICI)1097-0142(20000415)88:8<1964::AID-CNCR27>3.0.CO;2-1

[12] Strauss, A.J., Su, J.T., Dalton, V.M., Gelber, R.D., Sallan, S.E. and Silverman, L.B. (2001) Bony Morbidity in Children Treated for Acute Lymphoblastic Leukemia. Journal of Clinical Oncology, 19, 3066-3072. https://doi.org/10.1200/JCO.2001.19.12.3066

[13] Belgaumi, A.F., Al-Bakrah, M., Al-Mahr, M., Al-Jefri, A., Al-Musa, A., Saleh, M., Salim, M.F., Osman, M., Osman, L. and El-Solh, H. (2003) Dexamethasone-Associated Toxicity during Induction Chemotherapy for Childhood Acute Lymphoblastic Leukemia Is Augmented by Concurrent Use of Daunomycin. Cancer, 97, 28982903. https://doi.org/10.1002/cncr.11390

[14] Bonilla, M., Moreno, N., Marina, N., Reyes, G., Shurtleff, S.A., Downing, J.R., Behm, F.G., Harrison, P.L., Ribeiro, R.C., Pena, O., Crist, W.M. and Antillon, F.G. (2000) Acute Lymphoblastic Leukemia in a Developing Country: Preliminary Results of a Nonrandomized Clinical Trial in El Salvador. Journal of Pediatric Hematology/ Oncology, 22, 495-501. https://doi.org/10.1097/00043426-200011000-00004

[15] Metzger, M.L., Howard, S.C., Fu, L.C., Pena, A., Stefan, R., Hancock, M.L., Zhang, Z., Pui, C.H. Wilimas, J. and Ribeiro, R.C. (2003) Outcome of Childhood Acute Lymphoblastic Leukaemia in Resource-Poor Countries. Lancet, 362, 706-708. https://doi.org/10.1016/S0140-6736(03)14228-6

[16] Mostert, S., Sitaresmi, M.N., Gundy, C.M., Sutaryo, A. and Veerman, J. (2006) Influence of Socioeconomic Status on Childhood Acute Lymphoblastic Leukemia Treatment in Indonesia. Pediatrics, 118, e1600-e1606. https://doi.org/10.1542/peds.2005-3015

[17] Arora, R.S., Eden, T. and Pizer, B. (2007) The Problem of Treatment Abandonment in Children from Developing Countries with Cancer. Pediatric Blood Cancer, 49, 941-946. https://doi.org/10.1002/pbc.21127

[18] Bennett, J.M., Catovsky, D., Daniel, M.T., Flandrin, G., Galton, D.A., Gralnick, H.R. and Sultan, C. (1976) Proposals for the Classification of the Acute Leukaemias, French-American-British (FAB) Co-Operative Group. British Journal of Haematology, 33, 451-458. https://doi.org/10.1111/j.1365-2141.1976.tb03563.x

[19] Veerman, A.J. and Sumadiono, S. (2005) Twinning: A Rewarding Scenario for Development of Oncology Services in Transitional Countries. Pediatric Blood Cancer, 45, 103-106. https://doi.org/10.1002/pbc.20390 
[20] Veerman, A.J., Hahlen, K., Kamps, W.A., Van Leeuwen, E.F., De Vaan, G.A., Solbu, G., Suciu, S., Van Wering, E.R. and Van der Does-Van der Berg, A. (1996) High Cure Rate with a Moderately Intensive Treatment Regimen in Non-High-Risk Childhood Acute Lymphoblastic Leukemia. Results of Protocol ALL VI from the Dutch Childhood Leukemia Study Group. Journal of Clinical Oncology, 14, 911918. https://doi.org/10.1200/JCO.1996.14.3.911

[21] Hargrave, D.R., Hann, I.I., Richards, S.M., Hill, F.G., Lilleyman, J.S., Kinsey, S., Bailey, C.C., Chessells, J.M., Mitchell, C. and Eden, O.B. (2001) Medical Research Council Working Party for Childhood, Progressive Reduction in Treatment-Related Deaths in Medical Research Council Childhood Lymphoblastic Leukaemia Trials from 1980 to 1997 (UKALL VIII, $\times$ and XI). British Journal of Haematology, 112, 293-299. https://doi.org/10.1046/j.1365-2141.2001.02543.x

[22] Rubnitz, J.E., Lensing, S., Zhou, Y., andlund, J.T., Razzouk, S.B.I., Ribeiro, R.C. and Pui, C.H. (2004) Death during Induction Therapy and First Remission of Acute Leukemia in Childhood: The St. Jude Experience. Cancer, 101, 1677-1684. https://doi.org/10.1002/cncr.20532

[23] Slats, A.M., Egeler, R.M., Van der Does-Van den Berg, A., Korbijn, C., Hahlen, K., Kamps, W.A., Veerman, A.J. and Zwaan, C.M. (2005) Causes of Death-Other than Progressive Leukemia-In Childhood Acute Lymphoblastic (ALL) and Myeloid Leukemia (AML): The Dutch Childhood Oncology Group Experience. Leukemia, 19, 537-544. https://doi.org/10.1038/sj.leu.2403665

[24] Christensen, M.S. Heyman, M., Mottonen, M., Zeller, B., Jonmundsson, G. and Hasle, H.H. (2005) Nordic Society of Paediatric, Oncology, Treatment-Related Death in Childhood Acute Lymphoblastic Leukaemia in the Nordic Countries: 1992-2001. British Journal of Haematology, 131, 50-58. https://doi.org/10.1111/j.1365-2141.2005.05736.x

[25] Igarashi, S., Ohara, M.A.A., Kumagai, M., Saito, T., Okimoto, Y., Kamijo, T., Isoyama, K., Kajiwara, M., Sotomatsu, M., Sugita, K., Sugita, K., Maeda, M., Yabe, H., Kinoshita, A., Kaneko, T., Hayashi, Y., Ikuta, K., Hanada, R. and Tsuchida, M. (2005) No Advantage of Dexamethasone over Prednisolone for the Outcome of Standard- and Intermediate-Risk Childhood Acute Lymphoblastic Leukemia in the Tokyo Children's Cancer Study Group L95-14 Protocol. Journal of Clinical Oncology, 23, 6489-6498. https://doi.org/10.1200/JCO.2005.01.982

[26] Tang, Y., Xu, X., Song, H., Yang, S., Shi, S. and Wei, J. (2008) Long-Term Outcome of Childhood Acute Lymphoblastic Leukemia Treated in China. Pediatric Blood \& Cancer, 51, 380-386. https://doi.org/10.1002/pbc.21629

[27] Ribeiro, R. and Pui, C.H. (2008) Treatment of Acute Lymphoblastic Leukemia in Low- and Middle-Income Countries: Challenges and Opportunities. Leukemia and Lymphoma, 49, 373-376. https://doi.org/10.1080/10428190701882179

[28] Mostert, S., Sitaresmi, M.N., Gundy, C.M., Sutaryo, A. and Veerman, J. (2008) Parental Experiences of Childhood Leukemia Treatment in Indonesia. Journal of Pediatric Hematologyl Oncology, 30, 738-743. https://doi.org/10.1097/MPH.0b013e31817e4aad

[29] Mostert, S., Sitaresmi, M.N., Gundy, C.M., Sutaryo, A. and Veerman, J. (2008) Attitude of Health-Care Providers toward Childhood Leukemia Patients with Different Socio-Economic Status. Pediatric Blood \& Cancer, 50, 1001-1005. https://doi.org/10.1002/pbc.21324

[30] Sitaresmi, M.N., Mostert, S., Purwanto, I., Gundy, C.M., Sutaryo, A. and Veerman, J. (2009) Chemotherapy-Related Side Effects in Childhood Acute Lymphoblastic 
Leukemia in Indonesia: Parental Perceptions. Journal of Pediatric Oncology Nursing, 26, 198-207. https://doi.org/10.1177/1043454209340315

[31] Sitaresmi, M.N., Mostert, S., Schook, R.M., Sutaryo, A. and Veerman, J. (2010) Treatment Refusal and Abandonment in Childhood Acute Lymphoblastic Leukemia in Indonesia: An Analysis of Causes and Consequences. Psychooncology, 19, 361 367. https://doi.org/10.1002/pon.1578

[32] Sitaresmi, M.N., Mostert, S., Gundy, C.M., Sutaryo, A. and Veerman, J. (2008) Health-Care Providers' Compliance with Childhood Acute Lymphoblastic Leukemia Protocol in Indonesia. Pediatric Blood \& Cancer, 51, 732-736. https://doi.org/10.1002/pbc. 21698

[33] Sitaresmi, M.N., Mostert, S., Gundy, C.M., Sutaryo, A. and Veerman, J. (2009) Does Aid Reach the Poor? Experiences of a Childhood Leukaemia Outreach-Programme. European Journal of Cancer, 45, 414-419. https://doi.org/10.1016/j.ejca.2008.09.018

[34] Fuady, A. (2013) Moving toward Universal Health Coverage of Indonesia: Where Is the Position? Master's Thesis, Erasmus University Rotterdam, The Netherlands, 11. https://thesis.eur.nl/pub/15866

[35] Widjajanto, P.H., Sumadiono, S., Cloos, J., Purwanto, I., Sutaryo, S. and Veerman, A.J.P. (2013) Randomized Double Blind Trial of Ciprofloxacin Prophylaxis during Induction Treatment in Childhood Acute Lymphoblastic Leukemia in the WK-ALL Protocol in Indonesia. Journal of Blood Medicine, 4, 1-9.

https://www.dovepress.com/randomized-double-blind-trial-of-ciprofloxaci $\underline{\text { n-prophylaxis-during-indu-peer-reviewed-article-JBM }}$

[36] Te Poele, E.M., Bont, E.S., Marike Boezen, H., Revesz, T., Bokkerink, J.P., Beishuizen, A., Nijhuis, I.J., Oude Nijhuis, C.S., Veerman, A.J. and Kamps, W.A. (2007) Dexamethasone in the Maintenance Phase of Acute Lymphoblastic Leukaemia Treatment: Is the Risk of Lethal Infections Too High? European Journal of Cancer, 43, 2532-2536. https://doi.org/10.1016/j.ejca.2007.07.002

[37] Eden, O.B., Harrison, G., Richards, S., Lilleyman, J.S., Bailey, C.C., Chessells, J.M., Hann, I.M., Hill, F.G. and Gibson, B.E. (2000) Long-Term Follow-Up of the United Kingdom Medical Research Council Protocols for Childhood Acute Lymphoblastic Leukaemia, 1980-1997. Medical Research Council Childhood Leukaemia Working Party. Leukemia, 14, 2307-2320. https://doi.org/10.1038/sj.leu.2401962

[38] Conter, V., Arico, M., Valsecchi, M.G., Basso, G., Biondi, A., Madon, E., Mandelli, F., Paolucci, G., Pession, A., Rizzari, C., Rondelli, R., Zanesco, L. and Masera, G. (2000) Long-Term Results of the Italian Association of Pediatric Hematology and Oncology (AIEOP) Acute Lymphoblastic Leukemia Studies, 1982-1995. Leukemia, 14, 2196-2204. https://doi.org/10.1038/sj.leu.2401963

[39] Kamps, W.A., Veerman, A.J., Van Wering, E.R., Van Weerden, J.F., Slater, R. and Van der Does-Van den Berg, A. (2000) Long-Term Follow-Up of Dutch Childhood Leukemia Study Group (DCLSG) Protocols for Children with Acute Lymphoblastic Leukemia, 1984-1991. Leukemia, 14, 2240-2246.

https://doi.org/10.1038/sj.leu.2401964

[40] Veerman, A.J., Kamps, W.A., Van den Berg, H., Van den Berg, E., Bokkerink, J.P., Bruin, M.C., Van den Heuvel-Eibrink, M.M., Korbijn, C.M., Korthof, E.T., Van der Pal, K., Stijnen, T., Van Weel Sipman, M.H., Van Weerden, J.F., Van Wering, E.R.A. and Van der Does-Van den Berg, G. (2009) Dutch Childhood Oncology, Dexamethasone-Based Therapy for Childhood Acute Lymphoblastic Leukaemia: Results of the Prospective Dutch Childhood Oncology Group (DCOG) Protocol ALL-9 (1997-2004). Lancet Oncology, 10, 957-966. 
https://doi.org/10.1016/S1470-2045(09)70228-1

[41] Bostrom, B.C., Sensel, M.R., Sather, H.N., Gaynon, P.S., La, M.K., Johnston, K., Erdmann, G.R., Gold, S., Heerema, N.A., Hutchinson, R.J., Provisor, A.J. and Trigg, M.E.G. (2003) Children's Cancer, Dexamethasone versus Prednisone and Daily Oral versus Weekly Intravenous Mercaptopurine for Patients with Standard-Risk Acute Lymphoblastic Leukemia: A Report from the Children's Cancer Group. Blood, 101, 3809-3817. https://doi.org/10.1182/blood-2002-08-2454

[42] Pui, C.H. and Evans, W.E. (2006) Treatment of Acute Lymphoblastic Leukemia. New England Journal of Medicine, 354, 166-178.

https://doi.org/10.1056/NEJMra052603

[43] Hunger, S.P., Sung, L. and Howard, S.C. (2009) Treatment Strategies and Regimens of Graduated Intensity for Childhood Acute Lymphoblastic Leukemia in Low-Income Countries: A proposal. Pediatric Blood \& Cancer, 52, 559-565.

https://doi.org/10.1002/pbc.21889

Submit or recommend next manuscript to SCIRP and we will provide best service for you:

Accepting pre-submission inquiries through Email, Facebook, LinkedIn, Twitter, etc. A wide selection of journals (inclusive of 9 subjects, more than 200 journals)

Providing 24-hour high-quality service

User-friendly online submission system

Fair and swift peer-review system

Efficient typesetting and proofreading procedure

Display of the result of downloads and visits, as well as the number of cited articles

Maximum dissemination of your research work

Submit your manuscript at: http://papersubmission.scirp.org/

Or contact jct@scirp.org 